\title{
Anaerobic co-digestion of acetate-rich with lignin-rich wastewater and the effect of hydrotalcite addition
}

\author{
Lourdes Rodriguez-Chiang $a, b$, Jordi Llorca ${ }_{b}$ and Olli Dahl $a$ \\ a Department of Forest Products Technology, School of Chemical technology, Aalto University. P.O. Box 16300, \\ Vuorimiehentie 1, Espoo, Finland \\ b Institute of Energy Technologies, Technical University of Catalonia, Barcelona, Spain \\ * Corresponding author: Address: Department of Forest Products Technology, School of Chemical Technology, \\ Aalto University. P.O. Box 16300, Vuorimiehentie 1, Espoo, Finland. Tel: +358 (0) 505757593. Email: \\ lourdes.rodriguezchiang@aalto.fi (L.Rodriguez-Chiang)
}

\begin{abstract}
The methane potential and biodegradability of different ratios of acetate and lignin-rich effluents from a neutral sulfite semi-chemical (NSSC) pulp mill were investigated. Results showed ultimate methane yields up to $333 \pm 5 \mathrm{mLCH}_{4} / \mathrm{gCOD}$ when only acetate-rich substrate was added and subsequently lower methane potentials of $192 \pm 4 \mathrm{mLCH}_{4} / \mathrm{gCOD}$ when the lignin fraction was increased. The presence of lignin showed a linear decay in methane production, resulting in a $41 \%$ decrease in methane when the fraction of lignin had a 2.6 -fold increase. A negative linear correlation between lignin content and biodegradability was also observed. Furthermore, the effect of hydrotalcite $(\mathrm{HT})$ addition was evaluated and showed increase in methane potential ofup to $8 \%$ and a faster production rate. Higherlignin removal (7-12\% higher) and a more stable pH were also observedCOD removal efficiencies between 64 and $83 \%$ were obtained for all samples.
\end{abstract}

Keywords: methane potential; lignin; evaporator condensate; co-digestion;; hydrotalcite;

\section{Introduction}

A common issue of pulp and paper mills is their wastewater treatment. Given that their water usage is among the most intensive in industry, efforts on reducing water consumption in pulping processes and enhancing efficiency in their wastewater treatment has become a prioritized objective. Pulp and paper mills produce large volumes of wastewaters with numerous types of contaminants that are dependent on the type of pulping process and desired end-product (Bayr and Rintala 2012). Pulping effluents are characterized by high amounts of chemical oxygen demand (COD) and suspended solids (SS) as well as adsorbable organic halogens (AOX), and other inorganic compounds. Furthermore, lignin and its derivatives generate a strong color and additional high COD and turbid effluent (Kamali et al 2015). The current applied wastewater treatment technologies vary throughout the pulping industry, however a common and effective treatment is a combination of physicochemical processes with a biological treatment (aerobic and/or anaerobic)(Ashrafi et al. 2015). Anaerobic treatment of pulp and paper mill wastewater and sludge has gained increasing attention since the 
late 1980s and the number of installed anaerobic reactors in pulp and paper mills worldwide has more than doubled in the last decade (Meyes and Edwards 2014). Nevertheless, many hurdles exist to increase its widespread application, such as the complexity to digest lignocellulosic material which is typical to pulp and paper effluents. Other issues include the wide variations in effluent characteristics and the inhibition and toxicity of some common compounds found in pulping effluents such as sulfur, tannins, resin acids, and organochloride compounds (Ali and Sreekrishnan 2001).

Neutral sulfite semi-chemical (NSSC) is a type of pulping process where wood chips are initially cooked in a neutral solution of sodium sulfite and sodium bicarbonate. Sulfite ions react with the lignin in wood and the sodium bicarbonate acts as a buffer solution. The partly de-lignified soften wood chips are then mechanically disintegrated. This process is required to preserve high hemicellulose and lignin contents in order to retain the stiffness of the fibers in the semi-chemical fluting pulp (Oveissi et al 2014; Rehbein et al 2010; manskinen et al 2011). The wastewaters investigated in this study originate from a NSSC integrated pulp and board mill that produces high quality semi-chemical fluting. Fluting is the corrugated part between the surface liners in corrugated board. High quality and uniform fluting is needed to produce strong and durable corrugated board that is later used in packaging applications.

Major effluents of the NSSC mill are the condensates from the evaporation plant and the circulation water with fibers. Chemical recovery is practiced in the mill meaning there is no need to treat the spent liquor. Other minor effluents consist of collectable water from the liquor plant and power plant, leakage water from the landfill and sanitary water. All the effluents are collected, mixed and treated in an activated sludge plant followed by a sub-clarifier and flotation. Evaporator condensates may account for about $85 \%$ of the pulp mill's total effluent volume and $80-88 \%$ of the total chemical oxygen demand (COD) load. Evaporator condensates are acidic streams that contain mostly acetic acid (1.6-8.2 g/L), methanol (0.2-1.2 g/L), and furfural $(0.2-1.0 \mathrm{~g} / \mathrm{L})$ as the major organic components (Rintala and Puhakka 1994). As a effluent stream rich in acetic acid, it has and advantage of having readily degradable material for anaerobic digestion. Methanogenic bacteria can directly convert acetic acid into methane and carbon dioxide avoiding the initial hydrolysis step which is the ratelimiting step in the anaerobic digestion process (Appels et al 2008). Different studies have investigated the anaerobic treatment of evaporator condensate (Ekstrand et al 2013, Silva et al 2009, Driessen et al 2000, Benjamin et al 1984) and found that in spite of a general good running of the anaerobic digestion of this substrate, by itself it may cause inhibition and stability problems. Low concentrations had no significant effect but medium and higher concentrations caused interruption or permanent inhibition of the process. Silva et al 2009 also recognized that anaerobic treatment when an external carbon source is added to the reactor, specifically at high organic loads $\left(2 \mathrm{kgCOD} / \mathrm{m}^{3} \mathrm{~d}^{-1}\right.$ or higher) was beneficial and achieved a steady state of COD evolution.

The second largest effluent of the NSSC mill is the fiber circulation water, whose most significant characteristic is a high lignin content. The delignification treatment applied in the semi-chemical process and other pulping processes modifies and depolymerizes the lignin resulting in a complex mixture of dissolved lignin fractions that considerably vary from native lignin in chemical composition, molecular weight distribution and physical characteristics (Sierra-Alvarez and Lettinga 1991). Properties of lignin in wastewaters also vary according to the lignocellulosic raw material and the pulping process applied. The presence of lignin in wastewaters presents a major source of COD and organic matter however is it resistant to biological wastewater treatments. The 
microbial recalcitrance of lignin is due to its high molecular weight, chemical heterogeneity and the absence of regular hydrolysable intermonomeric linkages (Ruiz-Dueñas et al 2009). Lignin in aerobic conditions is depolymerized by lignolytic fungi (white-rot fungi) and some bacterial strains which have the unique enzyme needed to stimulate nonspecific extracellular oxidative reactions that depolymerize lignin (Kato et al 2015; Juan Wu et al 2005; Bugg et al 2011). Lignin degradation in anaerobic conditions is less studied; Kato et al 2015 reviewed different anaerobic bacteria able to degrade lignin and lignin-derived aromatics. Acetogenic bacteria are able to utilize the O-methyl group as the carbon and energy sources, however they are unable to degrade the aromatic ring structure. Similarly, some sulfate-reducing bacteria and fermentative bacteria use the Omethyl group as carbon and energy sources, and some of them can also decompose the aromatic rings. SierraAlvarez and Lettinga 1991 studies show that lignin degradation is limited to the low molecular weight derivatives and only monomers and oligomers of lignin $\left(<600 \mathrm{gmol}^{-1}\right)$ have been shown to be mineralized whereas higher molecular weight lignin is not anaerobically degradable. Interestingly, they also discovered that the inhibitory effect of lignin and its derivatives towards methanogenic bacteria originated from compounds in the low molecular weight fraction. Lignin derivatives with aldehyde groups or apolar substituents were highly toxic to methanogens. Moreover, various studies have proven the antimicrobial and antibiotic properties of lignin (Gregorova et al 2011; Erakovic et al 2014; Zemek et al 1979) in which polyphenol compounds of lignin are known to damage the cell membranes of microorganisms and cause lysis of the bacteria; this most likely influences the toxicity towards the anaerobic microbial community.

Numerous studies have stated the successful and beneficial result of co-digestion of easily degradable substrates with hard to degrade wastes (Cabbai et al 2013; Esposito et al 2012). Specifically to pulp and paper wastes, (Lin et al 2012; Hagelqvist 2013; Bayr and Rintala 2012) studies found that co-digestion improved the overall efficiency, resulted in higher methane yields and a more stable digestion process. These studies underline the importance of making highly polluted and hard to treat substrates into renewable energy recovery by co-digestion. In this investigation, the co-digestion of wastewaters rich in acetic acid and lignin was studied in batch Biochemical Methane Potential (BMP) tests at different ratio mixtures, for the first time. Furthermore, the addition of hydrotalcite (double layered hydroxides) was tested in order to measure its effect on the ultimate methane potential of substrates. Hydrotalcites (HTs) are anionic clays that have been used in a wide range of applications because of the possibility of designing them tailored to specific reactions and/or substrates. In recent years they have been studied in the treatment of various industrial wastewaters, as they can tackle different contaminants in water due to their high ion-exchange capacities for adsorption (Wajima 2014; Douglas et al). HTs have also been proven to increase hydrogen production in fermentation processes [Wimomsong both articles] and methane production in anaerobic digestion (Rodriguez-Chiang et al 2016). The objective of this study is to evaluate the methane potential from the co-digestion of different ratios of acetic acid and lignin-rich wastewaters and assess the inhibitory effect of lignin, furthermore evaluate the effects after hydrotalcite addition.

\section{Materials and methods}

\subsection{Inoculum and substrates}


The inoculum used to seed the batch reactors for the BMP experiments originated from the mesophilic anaerobic digester in Suomenoja municipal wastewater treatment plant located in Espoo, Finland. Fresh inoculum was collected and degassed at the same operating temperature $\left(37.0^{\circ} \mathrm{C}\right)$ prior to the start of the experiments. Characterization of the inoculum is shown in Table 1.

Two different substrates were used for the co-digestion experiments; evaporator condensate effluent originating from the sulfite evaporation plant from now on denoted as EC and fiber circulation effluent from now on denoted as FC. All substrate samples were provided by Stora Enso's Heinola Fluting Mill in Finland which produces high quality semi-chemical fluting which is used as a raw material in the corrugated board industry. EC is characterized by having high concentrations of acetic acid and furfural, and low solids, providing readily degradable material for methane production (Rintala and Puhakka 1994). FC is generally composed of high COD (usually above $8,000 \mathrm{mg} / \mathrm{L}$ ) provided from the high lignin content (25-50\%). The fresh substrates were analyzed using average values of triplicates and subsequently stored at $4^{\circ} \mathrm{C}$ prior to its use. Table 1 shows the substrates' characterization.

Table 1. Characteristics of inoculum and substrates. Values represent the average of triplicate samples and their standard deviation when indicated.

\begin{tabular}{|l|l|l|l|l|}
\hline Parameter & Unit & Inoculum & EC & FC \\
\hline $\mathrm{pH}$ & $\mathrm{s} . \mathrm{u}$. & 7.36 & 2.98 & 5.90 \\
\hline Chemical Oxygen Demand (COD) & $\mathrm{mg} / \mathrm{L}$ & $19,057 \pm 73$ & $2303 \pm 11$ & $11,572 \pm 26$ \\
\hline Total Solids (TS) & $\%$ & $2.79 \pm 0.01$ & $0.12 \pm 0.002$ & $0.98 \pm 0.02$ \\
\hline Volatile Solids (VS) & $\%$ & $1.55 \pm 0.01$ & $0.04 \pm 0.002$ & $0.52 \pm 0.007$ \\
\hline Moisture content & $\%$ & $97.22 \pm 0.01$ & $99.87 \pm 0.002$ & $99.02 \pm 0.02$ \\
\hline Conductivity & $\mathrm{mS} / \mathrm{cm}$ & 6.66 & 0.56 & 3.58 \\
\hline Total Organic Carbon (TOC) & $\mathrm{mg} / \mathrm{L}$ & $\mathrm{NA}$ & 961.4 & 4529 \\
\hline Inorganic Carbon (IC) & $\mathrm{mg} / \mathrm{L}$ & $\mathrm{NA}$ & 0.75 & 5.95 \\
\hline Total-N & $\mathrm{mg} / \mathrm{L}$ & $\mathrm{NA}$ & 0.00 & 0.295 \\
\hline Total-P & $\mathrm{mg} / \mathrm{L}$ & $\mathrm{NA}$ & 0.11 & 7.56 \\
\hline Volatile fatty acids (VFA) & $\mathrm{mg} / \mathrm{L}$ acetic acid & $\mathrm{NA}$ & $510 \pm 4$ & $\mathrm{NA}$ \\
\hline Furfural & $\mathrm{mg} / \mathrm{L}$ & $\mathrm{NA}$ & $23 \pm 0.2$ & $\mathrm{NA}$ \\
\hline Lignin & $\%$ & $\mathrm{NA}$ & $\mathrm{NA}$ & $44 \%$ \\
\hline
\end{tabular}

NA: not available

*Acid insoluble + Acid soluble lignin

\subsection{Hydrotalcite}

Hydrotalcite (HT) of $\mathrm{Fe}^{2+}-\mathrm{Zn}^{2+}-\mathrm{Mg}$-Al was added with each of the mixed ratios to a set of anaerobic reactors running in parallel. The HT was synthesized using the co-precipitation method and using a molar ratio of 3:1 of divalent and trivalent cations $\left(\mathrm{M}^{2+} / \mathrm{M}^{3+}\right)$. The HT was then characterized my FTIR, XRD and SEM in order to 
confirm characteristics of a well crystallized HT structure; full description can be found in previous research work (Rodriguez-Chiang et al 2016).

\subsection{Experimental set-up}

BMP tests were performed using an automatic methane potential test system (AMPTS II), which is a laboratory scale multiple batch system [Strömberg 2014]. Four different volume distribution ratios (based on COD content) of substrates were tested. Specific ratios were selected in order to simulate the real volume conditions existing in the operating mill. Volumes consisted of R1: 100/0, R2: 90/10, R3: 80/20 and R4: 70/30 of substrates EC/FC respectively. Moreover ratios of $\mathrm{R} 1+\mathrm{HT}, \mathrm{R} 2+\mathrm{HT}$ and $\mathrm{R} 3+\mathrm{HT}$ were tested with $\mathrm{HT}$ addition to evaluate its effect on the digestion process and final methane production. For this, Fe-Zn-Mg-Al hydrotalcite was added to the corresponding reactors in different quantities equivalent to $2 \% \mathrm{HT}$ addition of the initial substrate COD loading.

All samples were prepared in triplicates for statistical significance. The BMP tests were carried in $500 \mathrm{~mL}$ glass bottles with a working volume of $400 \mathrm{~mL}$ and the inoculum to substrate ratio (ISR) was maintained at 1:1 (COD) for all samples. The $\mathrm{pH}$ values of all the reactors were adjusted to 7 using $1 \mathrm{M} \mathrm{HCl}$ or $\mathrm{NaOH}$ when needed. To increase the buffering capacity $4 \mathrm{~g} / \mathrm{L}$ of $\mathrm{NaHCO}_{3}$ were added to each of the reactors at the start of the experiments. Triplicate blank samples with no substrate were run to determine the produced background methane originating from the inoculum alone. After filling each reactor with the corresponding volumes of inoculum and substrates, bottles where sealed with a hermetic rubber stopper attached to an automatic stirrer and placed in a water bath at a mesophilic temperature of $37.0 \pm 0.5^{\circ} \mathrm{C}$. Each reactor was then connected to a $3 \mathrm{M} \mathrm{NaOH}$ alkali solution with thymolphthalein $\mathrm{pH}$ indicator to chemically remove carbon dioxide $\left(\mathrm{CO}_{2}\right)$ and hydrogen sulfide $\left(\mathrm{H}_{2} \mathrm{~S}\right)$ from the biogas. Alkali solution bottles were attached to the measuring device and finally all reactors where flushed with pure nitrogen gas $\left(\mathrm{N}_{2}\right)$ for $5 \mathrm{~min}$, to create anaerobic conditions before start-up. To monitor process stability, samples from each reactor were withdrawn three times a week for $\mathrm{pH}$, COD and VFA analyses.

\subsection{Analytical methods}

Total solids (TS), volatile solids (VS), and moisture content in fresh samples of substrate and inoculum were determined gravimetrically following Standard Methods described in APHA [31]. COD was measured by closed reflux titration, Standard Method 5220. The $\mathrm{pH}$ measurements were performed using a $\mathrm{pH}$ meter Thermo Scientific model Orion 2-star pH-Benchtop. Conductivity was taken with a conductivity meter Orion Model 150. TOC and IC were measured using a TOC- $\mathrm{V}_{\mathrm{CPH}}$ analyzer (Shimadzu) according to SFS-ISO 8245, Total P and Total N measurements were conducted in a FIAstar 5000 analyzer according to ISO 15681-1 note 5241 and ISO 11905 and 13395 note 5202, respectively. $\mathrm{SO}_{3}$ and $\mathrm{SO}_{4}$ were measured by ion chromatograph Dionex ICS-1500 with column: ION PAC AS9-HC, 4×250 mm. VFA and furfural analysis was performed after centrifugation of samples at $11,000 \mathrm{rpm}$ for 10 minutes after which the supernatant was filtered and the liquid samples were analyzed by High Performance Liquid Chromatography (HPLC) using a Dionex UltiMate 3000 HPLC (Dionex, Sunnyvale, CA, 
USA) equipped with refractive index (RI) and ultraviolet (UV) diode array detectors and HyperREZ XP Carbohydrate $\mathrm{Ca}^{+}$column (Thermo Scientific, Waltham, MA, SA). The eluent used was a $0.0025 \mathrm{~mol} \mathrm{~L}^{-1}$ sulfuric acid solution at a flow rate of $0.8 \mathrm{ml} \mathrm{min}{ }^{-1}$. The column and the RI detector temperatures were fixed to $70^{\circ} \mathrm{C}$ and $55^{\circ} \mathrm{C}$, respectively. Acid-insoluble lignin or Klason lignin and acid-soluble lignin were analyzed after twostep acid hydrolysis according to Standard NREL/TP-510-42623. The lignin content was defined as the sum of acid-insoluble and acid-soluble portions; the latter was measured by UV-Vis spectroscopy (UV-2550, Shimadzu) at $280 \mathrm{~nm}$ and the former gravimetrically. The Quantitative real-time PCR technique with 16S rRNA-targeted oligonucleotide probes was employed to sample pellets after centrifugation for determination of microbial community (total methanogens).

\subsection{Data analysis}

Ultimate methane potentials and daily production rates of samples were measured using the AMPTS II from Bioprocess Control AB, Sweden (System Version 2.0 V1.08). By the principle of liquid displacement and buoyancy, volumes of gas are measured and corrected to standard temperature and pressure (STP) conditions at $273 \mathrm{~K}$ and $1013 \mathrm{mbar}$ air pressure. BMP was calculated as the accumulated methane produced per gram of COD added to each reactor, as determined in Eq. (1) [Stromberg et al 2014]:

$$
B M P=\frac{V_{\text {sample }}-V_{\text {inoc }} \frac{g C O D i s}{g C O D i b}}{g C O D_{\text {substrate }}}
$$

where $B M P$ is the normalized volume produced per gram COD of substrate added $\left(\mathrm{mLCH}_{4} / \mathrm{gCOD}\right), \mathrm{V}_{\text {sample }}$ is the mean value of accumulated methane produced from the reactor with both inoculum and substrate, $\mathrm{V}_{\text {inoc }}$ is the mean value of the accumulated volume produced by the blanks with only inoculum, $g C O D_{i s}$ is the mass of COD of the inoculum added in the sample, $g C O D_{i b}$ is the mass of COD of the inoculum added in the blanks, and $g C O D_{\text {substrate }}$ is the mass of COD of the substrate added in the reactor.

Anaerobic Biodegradability (BD) of the substrates can be estimated knowing the relation between the experimental methane yield (BMP) and the COD concentration of the sample. It is known that the theoretical methane yield of 1 gram COD is $350 \mathrm{~mL} \mathrm{CH}_{4}$ at STP (Buffiere et al 2006). Eq. (2) expresses the relation of BMP and biodegradability:

$$
B D=\frac{B M P\left(\mathrm{mLCH}_{4, S T P} / g C O D\right)}{350 \times C O D_{\text {waste }}(g C O D)}
$$

One-way analysis of variance (ANOVA) analysis was performed on all data with significance level set at $p \leq 0.05$ in order to determine if there is a statistical difference between replicas.

\section{Results and discussion}




\subsection{Methane potential}

Each of the samples demonstrated viability for methane production within the 20 days of digestion. Figs. 1 and 2 show the ultimate methane potential and gas production profiles for each ratio tested. Statistical analysis using ANOVA showed there was no significant variation with $p$-value $\leq 0.05$ between triplicate samples. It can be observed that R1 had the highest yield ( $324 \mathrm{mLCH}_{4} / \mathrm{gCOD}$ ) which is attributed to the higher VFA content (acetic acid) available in the EC substrate. Similar results for NSSC evaporator condensates ranging from 140 $340 \mathrm{mLCH}_{4} / \mathrm{gCOD}$ were found in other studies (Meyer 2014; Nilsson et al 1994, Arshad et al). A common setback of easily degradable substrates; such as acetate; is the possible accumulation of intermediate products through the anaerobic degradation pathway. When high concentrations of organic acids are produced; specifically acetate; aceticlastic methanogens have insufficient capacity to rapidly convert the acetate into $\mathrm{CH}_{4}$ and $\mathrm{CO}_{2}$. This results in the accumulation of alcohols and VFAs that influence the $\mathrm{pH}$ and cause inhibition in methane production. An ISR of 1:1 applied in the experiments proved sufficient quantity of methanogenic bacteria available for conversion of VFA. In this study R1; which was the mixed sample most prone to process instability; did not develop any serious process inhibition. However, a minor lag phase can me observed during days 5 through 8 (Fig. 2) followed by a spike of methane production until the ultimate yield is established. This is supported by the first and second maximum daily productions of R1 and R1+HT. Both samples had a VFA concentration of 2005-2064 mg/L on day 5, this VFA accumulation is translated into the lag phase observed. After that, a spike is observed where the maximum daily production was $38-52 \mathrm{mLCH}_{4} / \mathrm{gCOD}$ day ${ }^{-1}$ on day 13 , meaning a recovery of acid accumulation.

Table 2 reports the methane potential, biodegradability and COD removal of all samples. R2, R3 and R4 yielded $250 \pm 15,212 \pm 8$ and $192 \pm 4 \mathrm{mLCH}_{4} /$ gCOD respectively. Although lower than R1, methane yields were still among the average range of methane production of NSSC pulping effluents $\left(140-340 \mathrm{mLCH}_{4} / g C O D\right)$ considering the high content of lignin in the FC substrate. Methane potentials of co-digestion are much higher than the hypothetical mono-digestion of lignin-rich wastewater. R2 and R3 samples showed a somewhat similar pattern of degradation. Maximum daily production rates for $\mathrm{R} 2$ and $\mathrm{R} 2+\mathrm{HT}$ was $28-32 \mathrm{mLCH}_{4} / \mathrm{gCOD}^{-}$day

${ }^{1}$ achieved on day 5, whereas for $\mathrm{R} 3$ and $\mathrm{R} 3+\mathrm{HT}$ was $35-37 \mathrm{mLCH}_{4} / \mathrm{gCOD}$ day $^{-1}$ reached on day 9. All four curves of R1 and R2 achieved around $90 \%$ of their ultimate methane potential by day 9 and a plateau stage by day 12 (Fig. 2). Samples with HT addition followed the same tendency as their original replica, however a significant increment in methane yield was observed in all the HT samples ranging from 1.5-8\%. R1+HT also obtained a faster production rate. 


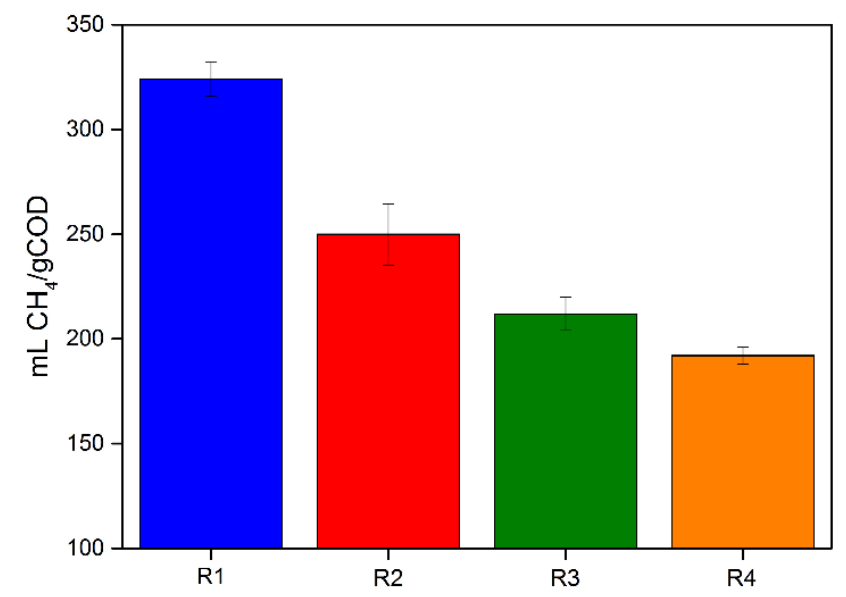

Fig. 1. Ultimate methane potential of mixed substrates and their standard deviation.

COD removal efficiencies between 64 and $83 \%$ were obtained for all samples. Samples with higher evaporator condensate content had higher COD removal (76-83\%) which express an efficient biodegradability. R3 and R4 samples including their replicates with $\mathrm{HT}$ addition had COD removals of $64-71 \%$, the lower range of COD removal can be correlated to the lower methane potential of the substrate. Biodegradability of samples had a similar pattern to COD removal rates. However, due to the high acetic acid content of R1 and R1+HT, the biodegradability of these samples are likely overestimated, since the assumption from Eq. 2 that the COD consists of purely carbohydrates provides a lower theoretical maximum production of methane than acetaterich substrates would deliver (Ekstrand et al 2013). Biodegradability for R2, R2+HT, R3, R3+HT and R4 demonstrated a lower range of $37-70 \%$.

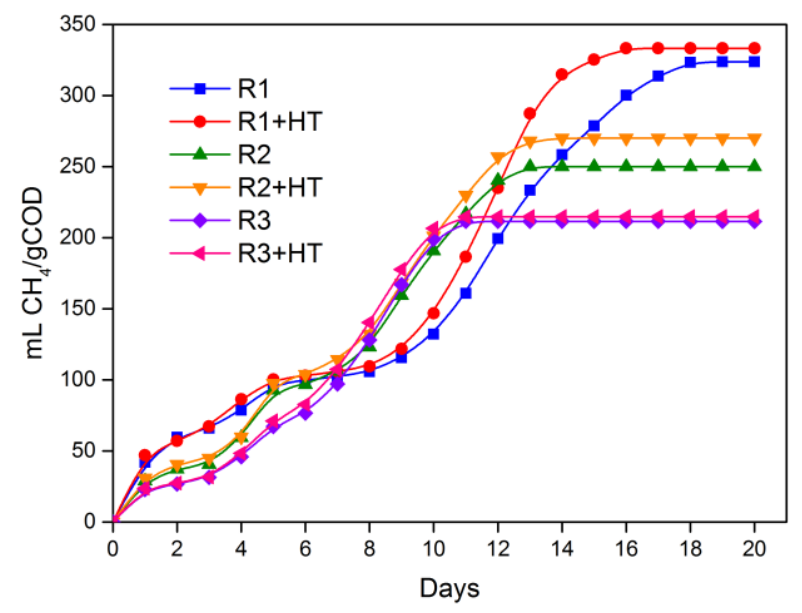

Fig. 2 Accumulated methane production of mixed substrates and mixed substrates with hydrotalcite addition, expressed as a function of time. 
Table 2. Final characterization of all mixed samples. Values represent the average of triplicate samples and their standard deviation when indicated.

\begin{tabular}{|l|l|l|l|l|l|l|}
\hline Sample & $\begin{array}{l}\text { Mix ratio } \\
(\mathrm{EC}: \mathrm{FC})\end{array}$ & $\begin{array}{l}\text { Methane yield } \\
(\mathrm{mL} / \mathrm{gCOD})\end{array}$ & $\begin{array}{l}\text { Lignin } \\
\text { removal (\%) }\end{array}$ & $\begin{array}{l}\text { COD } \\
\text { removal (\%) }\end{array}$ & $\begin{array}{l}\text { Biodegradability } \\
(\%)\end{array}$ & $\mathrm{pH}$ \\
\hline R1 & $100: 0$ & $324 \pm 8$ & $\mathrm{NA}$ & 82 & 185 & 7.5 \\
\hline R1+HT & $100: 0$ & $333 \pm 5$ & NA & 83 & 190 & 7.9 \\
\hline R2 & $90: 10$ & $250 \pm 15$ & $25 \pm 3$ & 76 & 65 & 7.9 \\
\hline R2+HT & $90: 10$ & $270 \pm 17$ & $28 \pm 6$ & 78 & 70 & 7.8 \\
\hline R3 & $80: 20$ & $212 \pm 8$ & $41 \pm 1$ & 75 & 46 & 7.7 \\
\hline R3+HT & $80: 20$ & $215 \pm 3$ & $44 \pm 2$ & 71 & 47 & 7.8 \\
\hline R4 & $70: 30$ & $192 \pm 4$ & NA & 64 & 37 & 7.5 \\
\hline
\end{tabular}

NA: Not available

\subsection{Control parameters}

$\mathrm{pH}$ measurements seemed to slowly increase throughout the experimental time between a range of 7- 8.15 Fig. 3. For R1 and R1+HT there is a slight drop starting at day 3 however increases by day 9 , this behavior in $\mathrm{pH}$ validates the VFA accumulation and minor lag phase identified previously. For all samples $\mathrm{pH}$ seemed, to some extent, influenced by samples with HT addition. Samples with HT appeared to have a more stable pH with less fluctuation through time. This may be due to the fact that HT nanoparticles have stable basic sites (RodriguezChiang et al 2016), the acidity caused by volatile fatty acid production may have been buffered by HT in the reactor therefore reducing changes in $\mathrm{pH}$.

COD reduction of samples fluctuated for the first 5 days. From day 6 onwards each ratio and its replica with HT addition had the same reduction behavior. VFA measurements of samples all followed the same patterns however with difference in concentrations, $\mathrm{R} 1$ and $\mathrm{R} 1+\mathrm{HT}$ being the highest. The maximum VFA production for all samples was on day 5 ranging from $1732-2064 \mathrm{mg} / \mathrm{L}$. By the end of the experiments there was no VFA measured. 

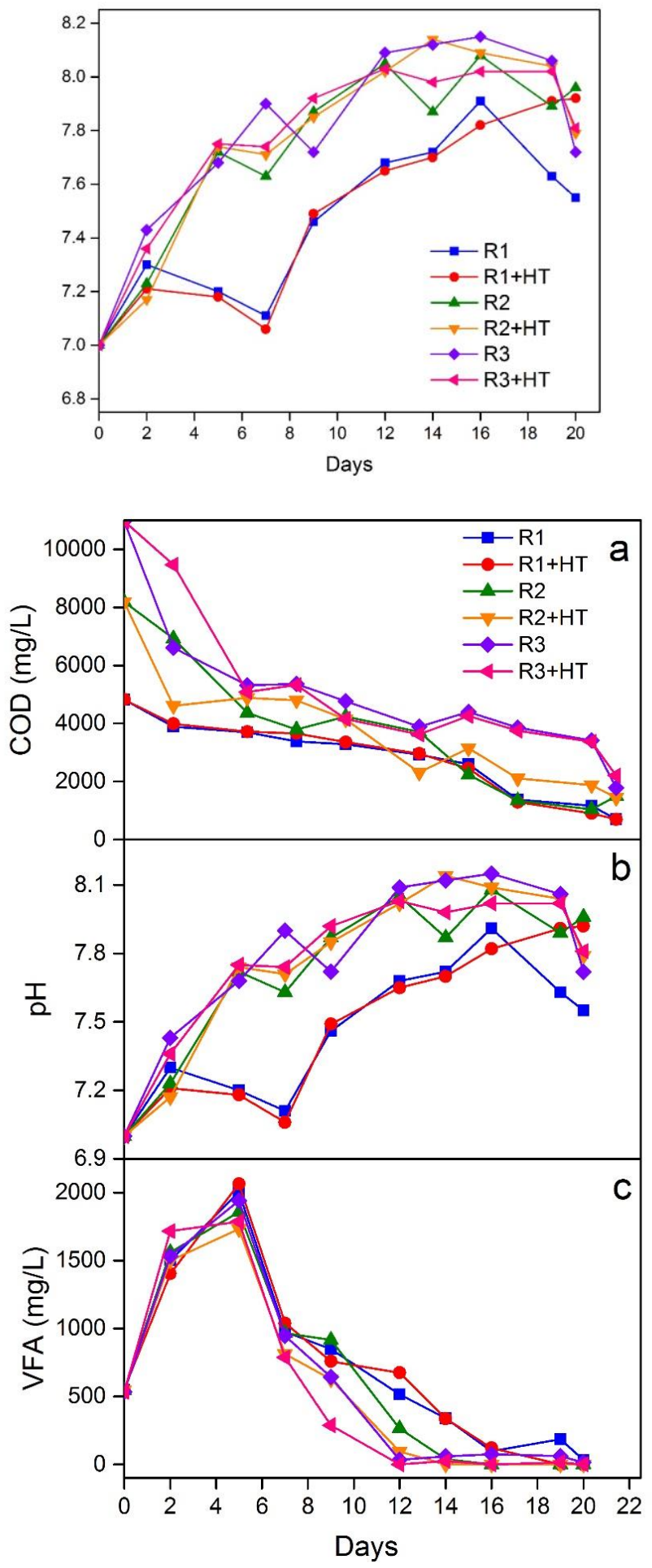

Fig. 3 Evolution of (a) COD, (b) pH variation and (c) volatile fatty acids concentration during anaerobic digestion in each reactor, expressed as a function of time. 
Sulfate $\left(\mathrm{SO}_{4}\right)$ concentrations varied significantly at initial and final phases of the experiment. NSSC effluents are rich in sulfur-containing compounds making sulfate-reducing bacteria (SRB) outcompete methanogenic bacteria and produce toxic sulfide during sulfate reduction (Xu et al 2012). Both sulfate and sulfite are known to act as electron sinks in anaerobic digestion and compete with methanogens for hydrogen. Jing et al (2013) studied the anaerobic performance when treating sulfate-rich wastewater and found that at a concentration of $3000 \mathrm{mg} / \mathrm{L}$ of sulfate and high organic loading rates of 6-18 $\mathrm{gCOD} / \mathrm{L} \mathrm{day}^{-1}$ sulfate removals remained between 28-42\% and COD removals were above $80 \%$. In this study, initial sulfate concentrations for both R1 and R2 was $67 \mathrm{mgSO}_{4} / \mathrm{L}$ and for R3 was $141 \mathrm{mgSO}_{4} / \mathrm{L}$. Final concentrations after anaerobic digestion in all reactors was reduced to a range of 0.1-0.7 $\mathrm{mgSO}_{4} / \mathrm{L}$ making sulfate reduction over $99 \%$. As initial concentration were not very high, sulfate may not have played an inhibiting role and there was most likely no hydrogen sulfide overproduction. Sulfite $\left(\mathrm{SO}_{3}\right)$ concentration at initial and final stages of the experiment had a negative correlation between each other. R1 had the highest concentration at the beginning of the experiment $(23 \mathrm{mg} / \mathrm{L})$ and the lowest at the end $(10 \mathrm{mg} / \mathrm{L})$; whereas R3 has the lowest concentration in the beginning $(4 \mathrm{mg} / \mathrm{L})$ and the highest by the end $(30 \mathrm{mg} / \mathrm{L})$. Sulfur in EC substrates is partially reduced to sulfide and released into the gas phase as $\mathrm{H}_{2} \mathrm{~S}$, however some organic sulfonates and sulfite may persist through the process and other organic sulfur compounds may be produced in the way (Ferguson and Benjamin 1985) .

DNA extraction and Quantitative real-time PCR ( $9 P C R$ ) were adapted to quantify the methanogen concentration in each anaerobic reactor. Differences in initial and final concentrations show population growth in all batch reactors (Table 3). Both R1 and R1+HT demonstrate a significant methanogenic growth of 253 and $293 \%$ respectively. The large and rapid increase in methanogen concentration is attributed to the Methanosarcinaceae gene which is known to increase with the degradation of acetate. The Methanosarcina species have a high growth rate and outcompete other species at a high acetate concentration, hence the high population growth in acetate-rich reactors R1 and R1+HT (Lee Changsoo et al 2009). R2 showed a reduced growth of 33\%. For R2+HT, R3 and R3+HT methanogenic growth was between 83-92\%. The predominance of Methanosarcina and Methanosaeta species has previously been reported during the anaerobic treatment of paper and pulp mill wastewaters, the latter known for having difficulties with growth and yield (Tabatabaei et al 2010, Roest et al 2004; Smith Kerry et al the forgotten methanogen). The presence of lignin fractions, specially low molecular weight fraction, has been demonstrated to induce methanogenic toxicity as well inhibition on bacterial growth. Some studies have also reported antimicrobial properties of lignin (Gregorova et al 2011; Erakovic et al 2014; Zemek et al 1979) that would explain the lower growth rate of samples with lignin compared with R1 and R1+HT.

Table 3. Microbial community population analysis of samples at initial and final stages of experimental testing.

\begin{tabular}{|l|l|l|l|}
\hline Sample & $\begin{array}{l}\text { Initial methanogen } \\
\text { concentration* }\end{array}$ & $\begin{array}{l}\text { Final methanogen } \\
\text { concentration }\end{array}$ & $\begin{array}{l}\text { Population growth } \\
(\%)\end{array}$ \\
\hline R1 & $1.22 \mathrm{E}+07$ & $4.31 \mathrm{E}+07$ & 253.28 \\
\hline $\mathrm{R} 1+\mathrm{HT}$ & $1.22 \mathrm{E}+07$ & $4.80 \mathrm{E}+07$ & 293.44 \\
\hline
\end{tabular}




\begin{tabular}{|l|l|l|l|}
\hline R2 & $4.43 \mathrm{E}+07$ & $5.87 \mathrm{E}+07$ & 32.51 \\
\hline R2+HT & $4.43 \mathrm{E}+07$ & $8.23 \mathrm{E}+07$ & 85.78 \\
\hline R3 & $4.36 \mathrm{E}+07$ & $7.99 \mathrm{E}+07$ & 83.26 \\
\hline R3+HT & $4.36 \mathrm{E}+07$ & $8.35 \mathrm{E}+07$ & 91.51 \\
\hline
\end{tabular}

*16S rRNA gene copies/mL. Values are average of triplicates.

\subsection{Effect of hydrotalcite addition}

The addition of Fe-Zn-Mg-Al hydrotalcite ( $\mathrm{HT}$ ) presented a positive effect on the methane potential of the tested samples. Ultimate methane yields were slightly increased by 1.4 - 8\% for samples with HT addition. $\mathrm{R} 1+\mathrm{HT}$ achieved a faster production rate reaching its ultimate methane yield by day 16 whereas R1 ay day 20 . $\mathrm{R} 2+\mathrm{HT}$ presented the highest increase in methane production up to $8 \%$ compared to R2 (Table 3). HT addition on R3 had no significant effect, the degradation profiles and methane yield of both remained the same. Both COD and lignin removal rates as well as biodegradability followed the same tendency, in which samples with HT were just slightly higher than samples with no HT addition. As previously stated, samples with HT seemed to have a more stable $\mathrm{pH}$. This is probably provided by the stable surface basic sites of the HT nanoparticles. the acidity caused by volatile fatty acid production may have been buffered by HT in the reactor therefore reducing changes in $\mathrm{pH}$. It was observed that microbial growth was higher in all samples containing HT compared to the samples with no HT addition. Studies have found that some microorganisms take advantage of nanoparticles, especially in anaerobic conditions, by transferring more efficiently electrons to acceptors (Beckers et al 2013). The increased surface area provided by HT nanoparticles and their action as biocatalysts leads to enhancement of microorganism activity and possible enhanced bacterial anchoring. This in turn, may be the cause of greater microbial growth in samples with HT addition (Rodriguez-Chiang et al 2016, Beckers et al 2013).

\subsection{Influence of lignin content on BMP}

Results demonstrated a linear decay in methane production when the fraction of lignin was increased in the feed. A negative linear correlation between lignin content and methane yield or biodegradability is shown in Fig. 4. The results show a correlation coefficient $\left(R^{2}\right)$ of 0.97 and 0.98 for methane yield and biodegradability respectively meaning a good fit. Statistical analysis using ANOVA showed a $p$-value $\leq 0.01$ for both curves. Li et al 2013 found a similar negative linear correlation between lignin content and the biomethane yields and biodegradabilities of lignocellulosic and manure wastes.

Lignin removal rates of samples ranged from $25-44 \%$. R1 and $\mathrm{R} 1+\mathrm{HT}$ had no lignin measured. $\mathrm{R} 2+\mathrm{HT}$ and $\mathrm{R} 3+\mathrm{HT}$ were $12 \%$ and $7 \%$ higher than their replicas without $\mathrm{HT}$ addition, respectively. Lignin is widely known for its extremely low degradability and its ability to hinder hydrolysis of cellulose thus limiting its bioavailability (Huifang Li et al 2015). In this study, lignin presence had a detrimental effect on the methane production resulting in a $41 \%$ decrease in production when the fraction of lignin had less than a 3 -fold increase. Triolo et al 
2011 studied the effect of lignin on the BMP of energy crops and animal manure and confirmed that the lignin fraction could be used to predict BMP for the combined model for energy crops and animal manures. Their findings included that lignin content negatively affects BMP more significantly in energy crops than in animal manure. However for industrial lignin, which is the lignin generated in large quantities as a by-product of chemical pulping of wood, conditions are different. This lignin differs significantly from native lignin in its structure and chemical composition, leading to formation of lower molecular weight lignin and other impurities such as sulfurous compounds or carbohydrates (Alekhina et al 2015). Sierra-Alvarez and Lettinga 1991 have found that low molecular weight lignin fractions are the responsible of the inhibitory effect of lignin and its derivatives towards methanogenic bacteria. From the microbial population analysis performed in the final samples of the reactors it is assumed that lignin content and its derivatives had a negative influence in microbial growth of methanogens, this can be observed from the reduced growth in reactor R2 and R3 which include lignin fractions.
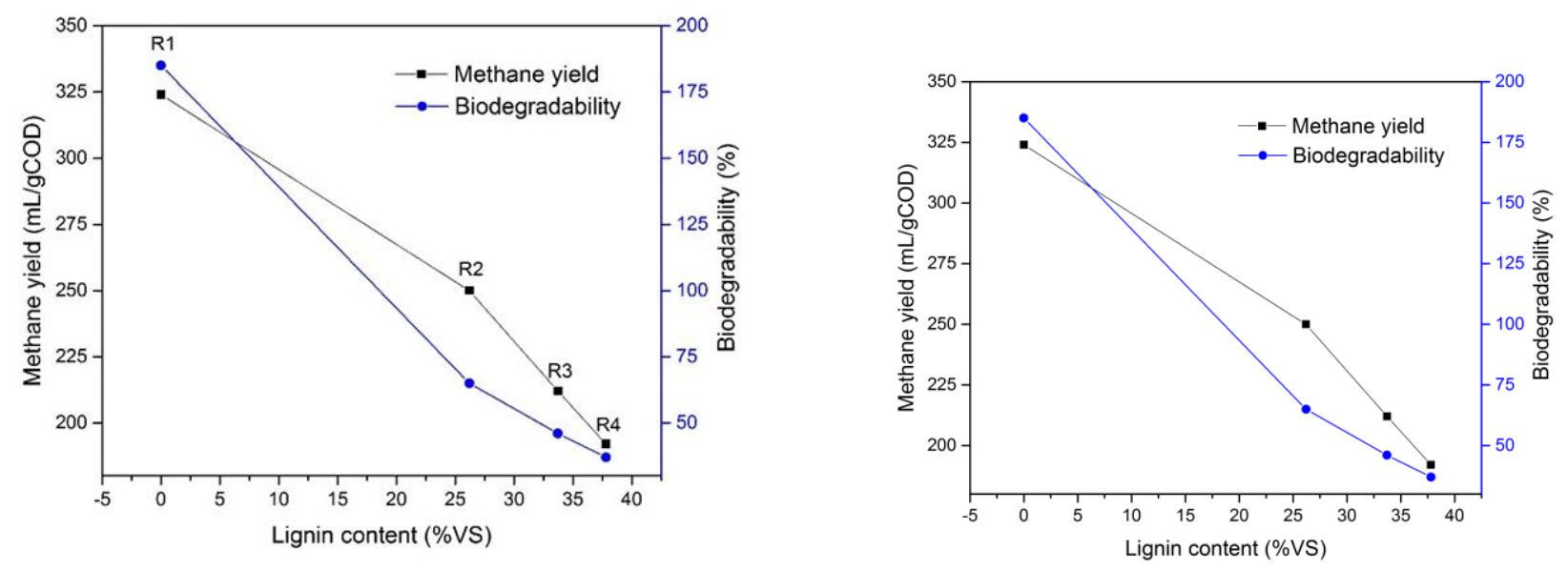

Fig.4. Correlation between lignin content, methane yield and biodegradability of NSSC effluents. Since I only have 4 set points the confidence interval for the correlation analysis is quite large. But I still think it appropriate to put the graph and mention it has a linear fit......

\section{Conclusions}

This study evaluated the methane potential of different ratios of effluents from a NSSC pulp mill. Methane yields ranged between $192-333 \mathrm{mLCH}_{4} / \mathrm{gCOD}$ where the greater the EC volumein the mix the greater the ultimate methane yieldCOD removal efficiencies between 64 and $83 \%$ were obtained for all ratio samples. A negative linear correlation between lignin content and methane yield was found, resulting in a $41 \%$ decrease in production when the fraction of lignin had a 2.6-fold increase.. The addition of Fe-Zn-Mg-Al hydrotalcite presented positive results such as faster production rate, better $\mathrm{pH}$ stability and higher lignin removal.. Co- 
digestion of both acetate and lignin rich effluents is suggested to improve the biodegradability of NSSCeffluents.

\section{Acknowledgements}

This research was accomplished under the support of the Erasmus Mundus SELECT+ Joint Doctoral Programme. The authors are grateful for the support of the staff at the Department of Forest Products Technology in Aalto University, the Institute of Energy Technologies in the Technical University of Catalonia and the staff at Stora Enso Heinola Fluting mill. J.L. is Serra Húnter Fellow and is grateful to ICREA Academia program.

\section{References}

[1] M. Kamali, Z. Khodaparast, Review on recent developments on pulp and paper mill wastewater treatment., Ecotoxicol. Environ. Saf. (2014) 1-17. doi:10.1016/j.ecoenv.2014.05.005.

[2] O. Ashrafi, L. Yerushalmi, F. Haghighat, Wastewater treatment in the pulp-and-paper industry: A review of treatment processes and the associated greenhouse gas emission, J. Environ. Manage. 158 (2015) 146157. doi:10.1016/j.jenvman.2015.05.010.

[3] T. Meyer, E.A. Edwards, Anaerobic digestion of pulp and paper mill wastewater and sludge, Water Res. 65C (2014) 321-349. doi:10.1016/j.watres.2014.07.022.

[4] M. Ali, T. Sreekrishnan, Aquatic toxicity from pulp and paper mill effluents: a review, Adv. Environ. Res. 5 (2001) 175-196.

[5] F. Oveissi, P. Fatehi, Production of modified bentonite via adsorbing lignocelluloses from spent liquor of NSSC process, Bioresour. Technol. 174 (2014) 152-158. doi:10.1016/j.biortech.2014.10.014.

[6] M. Rehbein, M. Pereira, G. Koch, O. Kordsachia, Topochemical investigation into the delignification of Eucalyptus globulus chips during semi-chemical sulfite pulping, Wood Sci. Technol. 44 (2010) 435-449. doi:10.1007/s00226-010-0363-1.

[7] K. Manskinen, H. Nurmesniemi, R. Pöykiö, Total and extractable non-process elements in green liquor dregs from the chemical recovery circuit of a semi-chemical pulp mill, Chem. Eng. J. 166 (2011) 954-961. doi:10.1016/j.cej.2010.11.082.

[8] J. a. Rintala, J. a. Puhakka, Anaerobic treatment in pulp- and paper-mill waste management: A review, Bioresour. Technol. 47 (1994) 1-18. doi:10.1016/0960-8524(94)90022-1.

[9] Appels, L., Baeyens, J., Degrève, J., \& Dewil, R. (2008). Principles and potential of the anaerobic digestion of waste-activated sludge. Progress in Energy and Combustion Science, 34(6), 755-781.

doi:10.1016/j.pecs.2008.06.002 
[10] F. Silva, H. Nadais, A. Prates, L. Arroja, I. Capela, Modelling of anaerobic treatment of evaporator condensate (EC) from a sulphite pulp mill using the IWA anaerobic digestion model no. 1 (ADM1), Chem. Eng. J. 148 (2009) 319-326. doi:10.1016/j.cej.2008.09.002.

[11] M.M. Benjamin, S.L. Woods, J.F. Ferguson, Anaerobic toxicity and biodegradability of pulp mill waste constituents, Water Res. 18 (5) (1984) 601-607.

Driessen, W., Tielbaard, M., Habets, L., \& Yspeert, P. (2000). Anaerobic treatment of evaporator condensates from the chemical pulp industry. VI Latin American IWA Workshop and Seminar on Anaerobic Digestion.

[12] R. Sierra-Alvarez \& G. Lettinga, The methanogenic toxicity of wastewater lignin and lignin related compounds, J.Chem.Tech.Biotechnol. (1991), 50, 443-455

[13] F.J. Ruiz-Dueñas, Á.T. Martínez, Microbial degradation of lignin: How a bulky recalcitrant polymer is efficiently recycled in nature and how we can take advantage of this, Microb. Biotechnol. 2 (2009) 164177. doi:10.1111/j.1751-7915.2008.00078.x.

[14] Kato, S., Chino, K., Kamimura, N., Masai, E., Yumoto, I., \& Kamagata, Y. (2015). Methanogenic degradation of lignin-derived monoaromatic compounds by microbial enrichments from rice paddy field soil. Scientific Reports, 5(August), 14295. doi:10.1038/srep14295

[15] J. Wu, Y.Z. Xiao, H.Q. Yu, Degradation of lignin in pulp mill wastewaters by white-rot fungi on biofilm, Bioresour. Technol. 96 (2005) 1357-1363. doi:10.1016/j.biortech.2004.11.019.

[16] T.D.H. Bugg, M. Ahmad, E.M. Hardiman, R. Rahmanpour, Pathways for degradation of lignin in bacteria and fungi., Nat. Prod. Rep. 28 (2011) 1883-96. doi:10.1039/c1np00042j.

[17] A. Gregorova, S. Redik, V. Sedlarik, F. Stelzer, Lignin-containing polyethylene films with antibacterial activity, NANOCON 2011 - Conf. Proceedings, 3rd Int. Conf. (2011) 184-189. http://www.scopus.com/inward/record.url?eid=2-s2.0-84923701095\&partnerID=tZOtx3y1.

[18] S. Erakovic, A. Jankovic, G.C.P. Tsui, C.Y. Tang, V. Miskovic-Stankovic, T. Stevanovic, Novel Bioactive Antimicrobial Lignin Containing Coatings on Titanium Obtained by Electrophoretic Deposition, Int. J. Mol. Sci. 15 (2014) 12294-12322. doi:10.3390/ijms150712294.

[19] Zemek J, Kosíková B, Augustín J, Joniak D. Antibiotic properties of lignin components. Folia Microbiol (1979), 24(6), 483-486.

[20] V. Cabbai, M. Ballico, E. Aneggi, D. Goi, BMP tests of source selected OFMSW to evaluate anaerobic codigestion with sewage sludge., Waste Manag. 33 (2013) 1626-32. doi:10.1016/j.wasman.2013.03.020.

[21] F. Esposito Giovanni; Frunzo, Luigi; Liotta, Flavia; Panico, Antonio and Pirozzi, Bio-Methane Potential Tests To Measure The Biogas Production From The Digestion and Co-Digestion of Complex Organic Substrates, Open Environ. Eng. J. 5 (2012) 1-8. 
[22] Lin, Y., Wang, D., Liang, J., \& Li, G. (2012). Mesophilic anaerobic co-digestion of pulp and paper sludge and food waste for methane production in a fed-batch basis. Environmental Technology, 33(23), 1-7.

doi:10.1080/09593330.2012.673012

[23] Hagelqvist, A. (2013). Batchwise mesophilic anaerobic co-digestion of secondary sludge from pulp and paper industry and municipal sewage sludge. Waste Management (New York, N.Y.), 33(4), 820-4.

doi:10.1016/j.wasman.2012.11.002

[24] Bayr, S., \& Rintala, J. (2012). Thermophilic anaerobic digestion of pulp and paper mill primary sludge and co-digestion of primary and secondary sludge. Water Research, 46(15), 4713-4720.

doi:10.1016/j.watres.2012.06.033

[25] Wajima, T. (2014). Removal of Bromide from Desalinated Water Using Hydrotalcite. International Journal of Environmental Science and Development, 5(2), 202-206. doi:10.7763/IJESD.2014.V5.478

[26] G.B. Douglas, L. a. Wendling, R. Pleysier, M.G. Trefry, Hydrotalcite Formation for Contaminant Removal from Ranger Mine Process Water, Mine Water Environ. 29 (2010) 108-115. doi:10.1007/s10230-0100106-4.

[27] P. Wimonsong, J. Llorca, R. Nitisoravut, Catalytic activity and characterization of Fe-Zn-Mg-Al hydrotalcites in biohydrogen production, Int. J. Hydrogen Energy. 38 (2013) 10284-10292.

doi:10.1016/j.ijhydene.2013.06.066.

[28] P. Wimonsong, R. Nitisoravut, J. Llorca, Application of Fe-Zn-Mg-Al-O hydrotalcites supported Au as active nano-catalyst for fermentative hydrogen production, Chem. Eng. J. 253 (2014) 148-154. doi:10.1016/j.cej.2014.05.047.

[29] Rodriguez-Chiang, L. M., Llorca, J., \& Dahl, O. P. (2016). Effect of Fe-Zn-Mg-Al hydrotalcites on the methane potential of synthetic sulfate-containing wastewater. Journal of Water Process Engineering, 10, 120-127. doi:10.1016/j.jwpe.2016.03.001

[30] S. Strömberg, M. Nistor, J. Liu, Towards eliminating systematic errors caused by the experimental conditions in Biochemical Methane Potential (BMP) tests., Waste Manag. 34 (2014) 1939-48. doi:10.1016/j.wasman.2014.07.018.

[31] APHA, Standard Methods for the Examination of Water and Wastewater, 20th ed., American Public Health Association, Washington, DC, 1998.

[32] M. Lehtomaki, THE TAMAN PROCESS : EXPERIENCES OF FULL-SCALE OPERATION AT ANJALA PAPER MILL, Wat. Sci. Tech. Vol.20 (1988) 99-105.

[33] Perttula, M., Konrasdottir, M., Pere, J., Kristjansson, J.K. \& Viikari, L. (1991). Removal of acetate from NSSC sulphite pulp mill condensates using thermophilic bacteria. Wat. Res., 25,599-604.

[34] T.L. Hansen, J.E. Schmidt, I. Angelidaki, E. Marca, J.L.C. Jansen, H. Mosbaek, et al., Method for determination of methane potentials of solid organic waste., Waste Manag. 24 (2004) 393-400. doi:10.1016/j.wasman.2003.09.009. 
[35] I. Angelidaki, B. K. Ahring, Effects of free long-chain fatty acids on thermophilic anaerobic digestion, Appl. Microbiol. Biotechnol., 37, 6 (1992) 808-812.

[36] M. Lesteur, V. Bellon-Maurel, C. Gonzalez, E. Latrille, J.M. Roger, G. Junqua, et al., Alternative methods for determining anaerobic biodegradability: A review, Process Biochem. 45 (2010) 431-440. doi:10.1016/j.procbio.2009.11.018.

[37] L.M. Rodriguez-Chiang, O.P. Dahl, Effect of Inoculum to Substrate Ratio on the Methane Potential of Microcrystalline Cellulose Production Wastewater, Bioresources, 10 (2015) 898-911.

[38] P. Buffiere, D. Loisel, N. Bernet, J.-P. Delgenes, Towards new indicators for the prediction of solid waste anaerobic digestion properties., Water Sci. Technol. 53 (2006) 233-241. doi:10.2166/wst.2006.254. 